\title{
Reflexóes sobre a investigação do raciocínio clínico em terapia ocupacional em saúde mental: o caso do Método Terapia Ocupacional Dinâmica ${ }^{1}$
}

\author{
Taís Quevedo Marcolino
}

Departamento de Terapia Ocupacional da Universidade Federal de São Carlos - UFSCar, São Carlos, SP, Brasil

\begin{abstract}
Resumo: O estudo sobre raciocínio clínico financiado pela Associação Americana de Terapia Ocupacional/AOTA e pela Fundação Americana de Terapia Ocupacional/AOTF no final da década de 1980, nos Estados Unidos, inaugurou a produção científica no tema e ofereceu um arcabouço inicial para a compreensão e a condução dos casos clínicos em Terapia Ocupacional. A maioria das pesquisas da área tem se preocupado com a investigação dos processos de raciocínio e aponta para a necessidade de se compreender o conteúdo dos pensamentos clínicos, ou como, a partir de seus referenciais, os terapeutas ocupacionais agem e elaboram hipóteses, de modo a produzir uma teoria explicativa. Nessa direção, esse ensaio apresenta resultados de duas pesquisas da autora interessada em compreender aspectos do raciocínio clínico de terapeutas ocupacionais que atuam a partir dos referenciais do Método Terapia Ocupacional Dinâmica/MTOD, evidenciando aproximações e distanciamentos no que se conhece sobre o raciocínio diagnóstico e o procedimental. A discussão traz à tona a necessidade de ampliar a produção de pesquisas dessa natureza, em especial junto aos profissionais brasileiros, bem como de divulgar o estudo desse tema na formação inicial e continuada de terapeutas ocupacionais.
\end{abstract}

Palavras-chave: Terapia ocupacional; Conhecimentos, atitudes e práticas em saúde; Saúde mental.

\section{Reflections on clinical reasoning in mental health occupational therapy: the case of the occupational therapy dynamic method}

\begin{abstract}
The Clinical Reasoning Study supported by the American Occupational Therapy Association/AOTA and the American Occupational Therapy Foundation/AOTF in the United States in the late 1980s, had inaugurated the scientific production in the field and offered an initial framework on clinical reasoning for understanding and conducting clinical cases in Occupational Therapy. Most of the researches in this field have focused on reasoning processes, and point out the need to understand the contents of clinical thoughts, or how occupational therapists act and elaborate hypotheses, based on their background knowledge, in order to produce an explanatory theory. In this direction, this article presents the results of two studies from the author focused on understanding aspects of clinical reasoning of occupational therapists who work sustained by Occupational Therapy Dynamic Method/ MTOD, highlighting similarities and differences on diagnostic and procedural reasoning. The discussion points out need to expand the production of this type of research, in particular with Brazilian professionals, as well as the dissemination and study of this subject in the initial and continuing training of occupational therapists.
\end{abstract}

Keywords: Occupational therapy; Health knowledge, attitudes and practices; Mental health.

\footnotetext{
Autor para correspondência: Taís Quevedo Marcolino, Departamento de Terapia Ocupacional da Universidade Federal de São Carlos, Rodovia Washington Luís, Km 235, CEP 13565-905, São Carlos, SP, Brasil, e-mail: taisquevedo@ gmail.com

Recebido em 2/4/2013; Revisão em 11/9/2013; Aceito em 19/10/2013.
} 


\section{$1 \mathrm{Um}$ modo de conhecer}

\section{a terapia ocupacional: as pesquisas sobre raciocínio clínico}

Desde 2003, quando iniciei minha formação em pesquisa, o tema central dos meus estudos tem sido o raciocínio clínico em Terapia Ocupacional, em especial de terapeutas ocupacionais que atuam a partir dos pressupostos do Método Terapia Ocupacional Dinâmica/MTOD (BENETTON, 1994, 2006).

Desse modo, neste ensaio, gostaria de apresentar os principais resultados das pesquisas sobre raciocínio clínico no âmbito internacional, bem como apresentar os resultados que venho encontrando e que ora se aproximam ora se afastam dessa literatura (MARCOLINO, 2005, 2009, 2012).

No que diz respeito ao Raciocínio Clínico em Terapia Ocupacional, o estudo encomendado pela Associação Americana de Terapia Ocupacional/AOTA e pela Fundaçáo Americana de Terapia Ocupacional/ AOTF no final da década de 1980, nos Estados Unidos, inaugurou a produção científica no tema e ofereceu um arcabouço inicial sobre o raciocínio clínico para a compreensão e a condução dos casos clínicos em Terapia Ocupacional. Sabemos, desde essa época, que nosso raciocínio é de base narrativa, que se preocupa com as particularidades dos casos, tanto para construir nossa compreensão, ao contar histórias sobre os pacientes, como para conduzir o processo terapêutico de modo a construir uma história terapêutica de sucesso, na qual o sucesso reside em possibilitar ao paciente a vivência de uma experiência significativa, que transforme seu modo de ver a vida e de se ver, na qual assuma um papel mais ativo (MATTINGLY, 1998; MATTINGLY; FLEMING, 1994).

Além disso, sabemos que o Raciocínio Clínico em Terapia Ocupacional também se apresenta com diferentes focos (raciocínio científico, diagnóstico, procedimental, narrativo, interativo, pragmático, ético), dependendo de para qual aspecto o terapeuta ocupacional volta sua atenção. Embora esses diferentes tipos de raciocínio sejam definidos por alguns autores (MATTINGLY; FLEMING, 1994; SCHELL; SCHELL, 2008) e utilizados de modo generalizado, algumas pesquisas, há tempos, vêm questionando não somente a generalidade dos termos mas também a de seus conteúdos. Será que, nas práticas em saúde mental, o raciocínio procedimental - definido em Mattingly e Fleming (1994) como aquele utilizado para encontrar procedimentos mais eficazes para melhorar o desempenho funcional da pessoa com determinado déficit - na verdade, náo seria um raciocínio interativo, que busca a promoção de relações interpessoais, como aponta Ward (2003)? Ou, como Roberts (1996), que questiona se o que vem sendo chamado de raciocínio interativo não poderia ser, na verdade, o conteúdo do raciocínio procedimental? Ou mesmo, Munroe (1996), que, ao analisar decisóes clínicas de 30 terapeutas ocupacionais experientes que trabalhavam em prática comunitária, evidencia que mais de $75 \%$ das decisóes tiveram justificativas interativas. Esses dados mostram que há ainda espaço para avançar nas pesquisas sobre o pensamento dos terapeutas ocupacionais e que, em parte, não há consenso em algumas questóes referentes ao tema, em especial no campo da saúde mental.

Schell e Schell (2008) também pontuam a relevância de se investigar a influência dos referenciais teóricos no desenvolvimento do pensamento clínico dos profissionais. Neste momento, sugiro aqui um leve afastamento do termo Raciocínio Clínico em Terapia Ocupacional para abrir espaço para investigar o raciocínio clínico dos terapeutas ocupacionais. E, na medida em que se for ganhando clareza do que sustenta nosso pensamento, no sentido de trazer à tona conteúdos implícitos da prática (SCHÖN, 1983), poderemos ter um cenário mais claro não somente dos processos - que mais vêm sendo estudados em termos de raciocínio clínico - mas, principalmente, dos conteúdos (ROBERTSON; GRIFFITHS, 2012) e de como, a partir de seus referenciais (background knowledge), os terapeutas ocupacionais agem e elaboram hipóteses, de modo a produzir uma teoria explicativa (SCHELL; SCHELL, 2008; THOMPSON, 2012).

Desse modo, a discussão que gostaria de disparar com este ensaio perpassa a necessidade de investigarmos a produção de cuidado em terapia ocupacional, no sentido de conhecer melhor e nomear o que fazemos - e de poder tecer relaçóes com o que se produz fora do Brasil, de modo a construir diálogos ao invés de um consumo unidirecional da produção internacional. Nesse caso, a investigaçáo do raciocínio clínico de terapeutas ocupacionais que atuam a partir dos pressupostos do MTOD, que possui uma grade teórica-metodológica consistente, pareceu favorecer esse diálogo. Além disso, deseja-se ampliar o debate sobre como os referenciais teórico-metodológicos, de fato, se oferecem como sustentação para o raciocínio clínico, pois, como ressaltam Helfriech e Kielhofner (1994), é no modo de compreensão e ação dos profissionais que os modelos têm seu crivo. 
$2 \mathrm{Um}$ modo de estruturar

\section{a prática em terapia ocupacional: o MTOD}

O Método Terapia Ocupacional Dinâmica/ MTOD vem sendo construído, ao longo dos últimos 40 anos, pela terapeuta ocupacional Jo Benetton e colaboradores, em um processo de teoria da técnica, que consiste na investigação da prática clínica da Terapia Ocupacional para produzir teorias explicativas dos fenômenos da prática e metodologias que sustentem a assistência.

O MTOD se funda no Paradigma da Terapia Ocupacional e que tem em Slagle e em sua técnica nomeada de treinamento de hábitos, elementos fundadores de uma terapia ocupacional que busca pela saúde e não pelo enfrentamento de doenças. A proposta é a de construir ou ampliar o cotidiano ampliando espaços de saúde na vida dos sujeitos alvo da assistência (BENETTON, 2005).

Embora detalhar o MTOD não seja a proposta, é importante apresentá-lo no que se refere à composiçáo de sua grade conceitual, que abarca as definiçôes de: relação triádica e seus termos (terapeuta ocupacional, sujeito alvo, atividades), de saúde, cotidiano, inserção social, ação educativa e função terapêutica. Além disso, propóe modos de proceder para a realização de diagnósticos em Terapia Ocupacional - o diagnóstico situacional, para a condução do processo terapêutico e da avaliação, todos centrados e/ou disparados pelo movimento dinâmico da relação triádica (BENETTON, 1994, 2010, 2012; MARCOLINO, 2012).

Ao se falar em construir ou ampliar o cotidiano como finalidade de uma inserção social, compreendida como a possibilidade de o sujeito ser, fazer e se relacionar a seu modo e com suas particularidades no social, tanto a composição do diagnóstico situacional como os procedimentos educativos e relacionais precisam estar imbuídos desses aspectos (ser, fazer e se relacionar). Em especial, na avaliaçáo (processual ou quando em trilhas associativas) busca-se que o próprio sujeito possa construir uma narrativa na qual a qualidade desses aspectos seja de sua pertença.

No MTOD, entâo, o significado do cotidiano do sujeito alvo, nos aspectos individuais e sociais, é o fundamento principal para a sua inserção social. É, enfim, por meio dessa significação que o sujeito alvo, como cidadão, toma em suas máos seu jeito de ser, para impor a sociedade que o receba desse jeito mesmo e que não precise esperar pela mudança social para nela se inserir. Nesse sentido, ele mesmo se torna agente dessa mudança (BENETTON, 2010, p. 39).
Desse modo, há um afastamento das propostas mais voltadas à aquisição de aspectos funcionais ou do desempenho ocupacional que náo considerem o cotidiano, a vivência individual no social e as relaçôes que se instauram nesse contexto.

\section{Um modo de investigar a prática em terapia ocupacional}

Antes de tecer as relaçóes entre o raciocínio clínico no MTOD e o que se discute na literatura internacional, gostaria ainda de ressaltar que as pesquisas que buscam estudar aspectos do raciocínio clínico utilizam metodologias que envolvem a narrativa e a reflexão sobre a ação, principalmente em situaçóes de inquirição, após a ocorrência da prática ou em situaçóes imaginárias, como casos hipotéticos. O que se quer acessar são aspectos implícitos da prática, dos quais os profissionais não necessariamente têm consciência (MATTINGLY; GILLETTE, 1991; UNSWORTH, 2005).

Nessa direção, os dados e as análises que vou apresentar são resultados de duas pesquisas, a primeira interessada em compreender aspectos educacionais dos procedimentos em terapia ocupacional e a segunda interessada em compreender aspectos do raciocínio clínico e do desenvolvimento profissional de terapeutas ocupacionais iniciantes em processo de formação continuada em uma especialização em Terapia Ocupacional em Saúde Mental. Ambas foram resultado do meu processo de formaçáo em pesquisa, mestrado e doutorado em Educação, respectivamente, e foram realizadas de acordo com os critérios éticos para a realização de pesquisas com seres humanos.

Os dados da primeira pesquisa caracterizam-se por narrativas escritas por uma terapeuta ocupacional experiente, de um caso que estava acompanhando em consultório particular. E sua análise utilizou as categorias para análise de processos reflexivos apresentadas por Hatton e Smith (1995).

$\mathrm{Na}$ segunda pesquisa, os dados foram compostos pela transcrição de 18 encontros presenciais de uma comunidade de prática profissional (WENGER, 1998) formada por seis terapeutas ocupacionais iniciantes, por duas terapeutas ocupacionais experientes e por mim, como pesquisadora e mentora do grupo, e por diários reflexivos e seus feedbacks, mantidos entre eu e as profissionais iniciantes, ao longo de 10 meses. Os diários reflexivos foram os principais materiais para a análise dos processos de raciocínio clínico. É importante lembrar que todas essas terapeutas ocupacionais ou tinham 
formação clínica no MTOD ou estavam sendo supervisionadas e buscavam atuar a partir dos pressupostos do MTOD.

Durante a análise dos diários da segunda pesquisa, percebi que seria infértil tentar me apoiar nas categorias dos diferentes tipos de raciocínio clínico existentes na literatura (MATTINGLY; FLEMING, 1994; SCHELL; SCHELL, 2008), pois trabalhava com terapeutas ocupacionais que tinham clareza, ou estavam fazendo grande esforço para ter clareza, de seus referenciais teórico-metodológicos, ou, mesmo, das percepções de como suas ações não estavam de acordo com o que elas acreditavam. Desse modo, deixei de lado tais categorias e parti para a análise de conteúdo dos trechos reflexivos de narrativas sobre a prática, que me possibilitaram o acesso ao raciocínio. Nesse processo fui encontrando pensamentos voltados para a construção da compreensão do caso e das justificativas para as açôes, em um diálogo com o referencial proposto pelo MTOD.

Com esse novo processo em mãos, pude revisitar os dados da primeira pesquisa e tecer uma conversa mais estruturada sobre o raciocínio clínico em Terapia Ocupacional.

\section{Raciocínio diagnóstico: um raciocínio narrativo que busca tecer relações entre os diferentes aspectos da vivência cotidiana}

Compreendemos o raciocínio diagnóstico como aquele que define nosso escopo de prática (ROBERTSON; GRIFFITHS, 2012), a construção do tipo de problemática à qual a profissão irá responder. Sobre o raciocínio diagnóstico, encontrei nas narrativas das terapeutas ocupacionais um tipo de reflexão - reflexão dialógica (HATTON; SMITH, 1995; MARCOLINO; MIZUKAMI, 2008) - que, a partir de situaçóes vivenciadas na relação triádica - ora no processo de realização de atividades, ora ao analisar a qualidade da relação terapêutica, ora na dinâmica que estava sendo construída entre os três termos -, as terapeutas ocupacionais explicitavam pensamentos ampliados, resgatando aspectos do passado, procurando organizar as informaçōes - de conteúdo bastante diversificado e sempre centradas nas especificidades dos casos - e explicitar suas hipóteses sobre a situação em que seu paciente se encontrava.

Desse modo, foi possível compreender que a construção do raciocínio diagnóstico, nomeado no
MTOD de diagnóstico situacional (BENETTON, 1994), é constante, não se restringe a uma etapa inicial do processo de terapia ocupacional, não se pauta somente em avaliações e protocolos, nem está atrelada somente a déficits e dificuldades (ROGERS; HOLM, 1991). Caracterizou-se por ser um raciocínio muito mais narrativo e que procura estabelecer relaçôes entre os diferentes aspectos que envolvem a vivência do cotidiano, oferecendo uma compreensão para sustentar procedimentos. Nesse sentido, parece um tipo de pensamento próximo do raciocínio condicional (FLEMING, 1991), que é justamente um raciocínio mais complexo, que cria uma imagem de futuro ao colocar junto aspectos do presente-passado-futuro.

Alguns exemplos podem ser apresentados, como quando uma terapeuta ocupacional, em um pensamento disparado no processo de realizaçấo de atividades, explicita suas observaçóes sobre o modo de a paciente fazer atividades e como isso vem se apresentando ao longo do processo.

Mostro uma outra forma que poderia usar a cola, [...] sugiro então que passe o dedo e o dedo passe no quadradinho, F. experimenta e parece gostar, repetindo essa forma. (Já teve momentos durante os atendimentos em que observei que $F$. consegue perceber algumas de suas dificuldades se angustiando com elas, ficando muitas vezes irritada consigo mesma, percebo como é exigente e detalhista, mas tem momentos em que percebo que não tem criticas sobre suas dificuldades, fazendo coisas grotescas sem perceber. O mesmo acontece com o fato de se sujar, às vezes percebo-a cuidadosa, mas já observei momentos em que parece sentir prazer de se sujar, me sujar e sujar os móveis, e momentos de muitos descuidos consigo mesma, materiais e com as atividades), relato de terapeuta ocupacional experiente (MARCOLINO, 2005, p. 119-120).

Ou quando uma terapeuta ocupacional iniciante apresenta uma narrativa mais complexa, mas que apresenta um raciocínio diagnóstico da posição ocupada pela paciente.

Acredito que esse é um importante caminho com Joana, o de ao mesmo tempo possibilitar que toda essa vivencia venha à tona e possa ser acolhida e menos solitária, assim como o de encontrar outras coisas que deem a Joana um papel de ser humano, [...] que possa se constituir, se reconhecer e ser reconhecida como alguém que além de tudo isso tenha habilidades, potenciais que ofereçam a ela a dignidade de sentir-se passivel de trocas, de experiências, de encontro com o outro, que não o reduza à questão da patologia e suas consequências. [...] Sinto Joana tão cristalizada 
nesse lugar, e ao mesmo tempo em que ela me solicita nas entrelinhas uma mudança, ela também se sente confortável nesse lugar mais conhecido, e qualquer caminho a tomar implica em tanto sofrimento., relato da terapeuta ocupacional Clarice (MARCOLINO, 2009, p. 215).

Uma outra terapeuta ocupacional iniciante também apresenta reflexôes iniciais sobre a repercussão da cisão no cotidiano, causada pelo adoecimento mental.

[...] ao fato de não estar mais trabalhando, sendo que sempre foi alguém muito ativo, que há cinco meses vinha trabalhando no Paraná, em um cargo importante em uma empresa, voltando para São Paulo somente aos finais de semana. Imagino que esta abrupta mudança de rotina possa estar lhe causando minimamente algum estranhamento e algum nivel de adaptação a ela., relato da terapeuta ocupacional Mariana (MARCOLINO, 2009, p. 215).

E, ainda neste outro excerto, a terapeuta ocupacional iniciante volta suas reflexóes para a compreensão da dimensão subjetiva e relacional, que também integra o diagnóstico situacional.

Nosso atendimento durou duas horas. Foi muito intenso, o estar com ela é muito intenso. Parece que não filtra o que sente, suas emoçóes são brutas, o que sente e pensa simplesmente sai, e muito na e em relação ao outro que está com ela., relato da terapeuta ocupacional Mariana (MARCOLINO, 2009, p. 226).

Todos estes aspectos (o repertório para realizar atividades, a relação que se estabelece com a doença, o impacto da doença nas atividades cotidianas e a construção de sentidos sobre ela, a maneira de se relacionar com o outro) e tantos outros mais que se fizerem necessários, de acordo com as particularidades do caso, são chamados à composição de um diagnóstico em terapia ocupacional quando esse processo está voltado para a ampliação ou construção de cotidiano. E, nesta direção, essas compreensões formam a base para se pensar em procedimentos educativos e relacionais.

\section{Raciocínio Procedimental:} ações intencionais para agir
dinamicamente na relação
triádica

No que se refere aos procedimentos, também precisei de um afastamento do que Mattingly e
Fleming (1994) nomearam raciocinio procedimental, como um pensamento voltado para compreender as consequências das condições clínicas na funcionalidade do paciente, de encontrar os procedimentos mais eficazes para melhorar o desempenho funcional da pessoa com determinado déficit, ao procurar encontrar a ação que resultará na melhora da função, mas a partir dos detalhes da situação particular do paciente.

Por um lado, estamos distantes do foco da melhora funcional, a não ser de uma funcionalidade exercida em um cotidiano (MARCOLINO, 2003), pois buscamos a inserção social como finalidade de uma terapia ocupacional.

Por outro lado, também consideramos o raciocínio procedimental como a construção das açôes intencionais do terapeuta ocupacional para agir dinamicamente na relação triádica. Nesse sentido, a relação/interação com o paciente não pode se restringir somente à busca de sua colaboração no tratamento, como apresentam Schell e Schell (2008). Mas, sim, o manejo da relação terapêutica é entendido como procedimento e, desse modo, implica na compreensão do terapeuta sobre os aspectos relacionais do paciente e dos modos de se colocar na relação para que novas mudanças possam ocorrer.

O raciocínio procedimental, encontrado na forma de descriçóes reflexivas (HATTON; SMITH, 1995; MARCOLINO; MIZUKAMI, 2008), que são pensamentos que explicitam justificativas para as ações, abarcou aspectos educacionais - a partir dos modos de aprendizagem específicos de cada paciente - e relacionais, nos quais o terapeuta deve oferecer gestos e atitudes que impulsionem o sujeito a sair de sua inatividade ou paralisia.

[...] fiquei observando como ela estava conseguindo usar o bastão sem deixar a tinta em excesso, acabou pintando toda a madeira, estava usando a tinta de alto relevo para pintar sem relevo, mas resolvi náo intervir, pois estava ficando bem acabado e tinha conseguido sozinha achar uma forma (plasticidade da técnica). Fiquei pensando que para algumas dificuldades ela conseguia criar estratégias criativas para sair, mas que muitas vezes, ou melhor, na maioria das vezes isso não acontecia, mas estava observando qual era a frequência no tempo, se vem aumentado ou não com o tratamento [...], relato de terapeuta ocupacional experiente (MARCOLINO, 2005, p. 120).

[...] vou até Helena, cumprimentando-a. Novamente, a paciente se levanta e me dá as costas. Neste momento, decido dizer a ela como 
me sentia em relação a como a percebia. Digo-lhe que percebia intenso sofrimento nela, o que muito me angustiava, na medida em que me despertava muita vontade de cuidar, mas que não sabia como acessá-la, como me aproximar. Helena começa a chorar muito, mas continua de costas para mim e sem me dirigir a palavra. [...] Helena me atordoa, de tanta intensidade. Tanto na alegria, quanto na tristeza. Me convida a uma realidade, a qual não me preocupei em descrever tanto aqui, mas que é muito diferente e também muito real da perspectiva da qual Helena parte. Tem muito a ver com sua história de vida e com a dinâmica familiar: cada um por si, ninguém pode contar ou confiar em ninguém, mesmo porque, pouco se enxerga o outro, e se náo o enxergamos, logo ele não existe. [...] Penso que a angustia, da qual the falei, é um sentimento de contratransferência que sentia ao estar com ela, ao vê-la sofrer e sem conseguir cuidar. De alguma forma, divido com ela essa minha sensação, responsabilizando-a quanto ao que me causava e lhe mostrando tanto a minha humanidade quanto a sua. A partir dai, parece que é possivel compartilharmos coisas., relato da terapeuta ocupacional Mariana (MARCOLINO, 2009, p. 187).

Esses dois excertos exemplificam açóes intencionais das terapeutas ocupacionais na conduçáo do processo terapêutico. Como pontua Benetton (1994), os procedimentos podem ser praticamente infinitos, na medida em que trabalhamos com o ser humano, mas, para o MTOD, são guiados para a busca de movimentos dinâmicos entre os três termos da relação triádica. Nesse sentido, "não interferir em um processo de realização de atividades" e "dizer o que se sente na relaçáo" aparecem como procedimentos que sustentam a continuidade da aprendizagem e abrem espaço para o surgimento do novo.

Ainda nessa direçáo, procedimentos de avaliaçáo também foram encontrados - dizem respeito a como o terapeuta ocupacional ajuda o paciente a tomar posse das aquisiçôes e transformaçóes que acontecem no processo terapêutico. A avaliaçáo se dá, principalmente, centrada na análise de atividades, ora de modo processual, durante os atendimentos, ora no momento da realização das trilhas associativas (BENETTON, 1994, 2006), como podemos ver nos excertos a seguir:

Falo que tinha escutado [...] duas grandes conquistas, e que achava que uma estava relacionada com a outra, uma da tentativa de dormir sozinha e outra de trazer amigas para perto. F. sorri parecendo fazer sentindo essas associaçōes. [...]", relato de terapeuta ocupacional experiente (MARCOLINO, 2005, p. 117).
[...] Sugiro que as separe em dois grupos, um nas que havia dado para sua mãe e outras que deu para outras pessoas, F. [...], pensa e fala que a maioria deu para sua mãe, pois ama muito ela, mais do que tudo, e que adora dar presente para ela, fica em silêncio (parece perplexa com que estava vendo), tenta colocar algumas atividades no outro grupo, mas náo consegue, [...] vejo a angustia e resolvo lembrá-la dos imãs, F. parece aliviada, [...] pega o papel com a lista na mão e coloca bem perto do seu rosto e fala que realmente não tinha feito nada para ela e que entendia o que eu queria falar em atendimentos anteriores, mas que, agora estava fazendo o "altarzinho" para ela. Aponto entusiasmadamente então a primeira atividade pensada e programada especialmente para ela. F. pega o pincel e continua a pintar., relato de terapeuta ocupacional experiente (MARCOLINO, 2005, p. 106-107).

\section{Considerações finais}

No contato com alunos e profissionais, venho refletindo o quanto dizemos que temos uma prática criativa e centrada no sujeito e, de fato, a clínica e nossos pacientes nos dizem isso, mas o quanto ainda é difícil colocar em palavras a prática. No Brasil há poucas pesquisas sobre o pensamento do terapeuta ocupacional, poucas publicações, em forma de traduçóes ou livros texto, e parece-me que há pouco uso desse conteúdo na formação inicial e continuada.

Ao olhar para as publicaçóes brasileiras de trabalhos acerca da prática é comum encontrarmos trabalhos cujo discurso da prática valoriza os aspectos do cotidiano como alvo de nossas açôes profissionais, muito mais do que favorecer a participaçáo em ocupaçôes (DRUMMOND, 2007; GALHEIGO, 2003). Mas há, nesse contexto, um universo muito rico que precisa ser desvelado e que diz respeito a compreender as açóes profissionais a partir dos referenciais adotados pelos terapeutas ocupacionais, a compreender e avaliar a coerência entre o que fazemos e dizemos que fazemos. Além disso, vislumbro a necessidade de compreender como terapeutas ocupacionais vêm pensando suas açôes, e a quais problemas vêm sendo chamados a responder, para que esse conhecimento possa retornar à formação em um movimento posterior. $\mathrm{Ou}$, ainda, nos moldes educacionais praticados no Brasil faltam propostas de investigação que busquem compreender processos de apropriação de modos mais complexos de raciocínio durante a formaçáo inicial. 
Circunscrever as pesquisas aqui apresentadas a um referencial teórico-metodológico possibilitou um maior aprofundamento no tipo de pensamento que é sustentado pelo MTOD, e, consequentemente, o surgimento de inúmeras outras perguntas, em um jogo entre teoria e prática, as quais clamam por novas investigaçóes. Um exemplo disso é a necessidade de se investigar o raciocínio associativo, próprio do MTOD, que vai ligando e tecendo as relaçôes entre as informaçóes obtidas e as hipóteses construídas no processo diagnóstico e que se oferece de matriz para procedimentos em busca da construçáo de narrativas clínicas (BENETTON, 2012).

Em especial, na prática de Terapia Ocupacional na Saúde Mental, cuja natureza é mais subjetiva e interdisciplinar, nomear ações profissionais e delimitar especificidades torna-se um grande desafio (LANCMAN; JUNS, 2011), mas vislumbro que esse tipo de abordagem investigativa pode contribuir para trazer luz a esse cenário.

Nesse processo, pesquisa, clínica e formação caminham juntas, como diz uma das terapeutas ocupacionais que participou de uma das pesquisas:

Foi através dos diários, dos encontros e das devolutivas, que aprendi na prática o poder e a necessidade que têm a organização da escrita, das trocas, do relatar e pensar prática e teoricamente os casos atendidos, os serviços, as narrativas, as composiçóes da profissão e suas variantes. Fui me dando conta que por não desempenhar uma profissão que funciona na base da causa-efeito, além de suas outras particularidades, não poderia seguir a mesma linha de pensamento e principalmente de trocas (enquanto discussōes de casos), me baseando nessa norma quase dominante no meio médico ao qual estamos inseridas, e que posso sim, utilizar uma fala por vezes mais descritiva, sem tanto rigor psicopatológico, mais voltado para meu olhar e conceituaçóes teóricas, e mesmo assim, conquistar meu espaço e ser aceita profissionalmente. É essencial então, falar que por todo esse caminho percorrido, minha prática sofreu uma alteração importante e como consequência a minha forma de conceber a profissão (identidade) e meu modo de estar diante dela e das outras áreas com as quais dialogo constantemente., relato da terapeuta ocupacional Clarice (MARCOLINO, 2009, p. 183).

Que esse relato, fruto de um processo de formação em uma pesquisa-ação, assim como todo o texto, possa contribuir para as discussóes sobre a prática da Terapia Ocupacional, sobre a construção do raciocínio clínico, sobre a importância de colocar o que fazemos, como o fazemos e o que pensamos sobre o que fazemos como objetos de estudo em nossas pesquisas, que estão em franco crescimento no território nacional.

\section{Referências}

BENETTON, M. J. A terapia ocupacional como instrumento nas açôes de saúde mental. 1994. 190 f. Tese (Doutorado em Saúde Mental)-Universidade de Campinas, Campinas, 1994.

BENETTON, M. J. Além da opinião: uma questão de investigação para a historicização da Terapia Ocupacional. Revista CETO, São Paulo, v. 9, n. 9, p. 4-8, 2005.

BENETTON, M. J. Trilhas associativas: ampliando subsídios metodológicos à clínica da terapia ocupacional. Campinas: Arte Brasil, 2006.

BENETTON, M. J. O encontro do sentido de cotidiano na Terapia Ocupacional para a construção de significados. Revista CETO, São Paulo, v. 12, n. 12, p. 32-39, 2010.

BENETTON, J. A narrativa clínica no Método Terapia Ocupacional Dinâmica. Revista CETO, São Paulo, v. 11, n. 11, p. 4-8, 2012.

DRUMMOND, A. F. Fundamentos da Terapia Ocupacional. In: CAVALCANTI, A.; GALVÃO, C. (Org). Terapia Ocupacional: fundamentação \& prática. Rio de Janeiro: Guanabara Koogan, 2007. p. 10-17.

FLEMING, M. The therapist with three track-mind. American Journal of Occupational Theapy, Bethesda, v. 45, n. 11, p. 1007-1014, 1991. http://dx.doi.org/10.5014/ ajot.45.11.1007

GALHEIGO, S. M. O cotidiano na terapia ocupacional: cultura, subjetividade e contexto histórico-social. Revista de Terapia Ocupacional da Universidade de São Paulo, São Paulo, v. 14, n. 3, p. 104-109, 2003.

HATTON, N.; SMITH, D. Reflection in teacher education: towards definition and Implementation. Teaching \& Teacher Education, Amsterdan, v. 2, n. 1, p. 33-49, 1995.

HELFRIECH, C.; KIELHOFNER, G. Volitional narratives and the meaning of therapy. The American Journal of Occupational Therapy, Bethesda, v. 48, n. 4, p. 319-326, 1994. http://dx.doi.org/10.5014/ajot.48.4.319

LANCMAN, S.; JUNS, A. G. O trabalho interdisciplinar no CAPS e a especificidade do trabalho do terapeuta ocupacional. Revista de Terapia Ocupacional da Universidade de São Paulo, Sáo Paulo, v. 22, n. 1, p. 27-35, 2011.

MATTINGLY, C. Healing dramas and clinical plots: the narrative structure of experience. Cambridge: Cambridge University Press, 1998. http://dx.doi.org/10.1017/ CBO9781139167017

MATTINGLY, C.; FLEMING, M. H. Clinical reasoning: forms of inquiry in a therapeutic process. Philadelphia: F. A. Davis Company, 1994

MATTINGLY, C.; GILLETTE, N. Anthropology, occupational therapy and action research. The American 
Journal of Occupational Therapy, Bethesda, v. 45, n. 11, p. 972-978, 1991.

MARCOLINO, T. Q. Sobre reabilitar o que não se reabilita. Revista CETO, São Paulo, v. 8, n. 8, p. 54-58, 2003.

MARCOLINO, T. Q. A dimensão pedagógica nos procedimentos de Terapia Ocupacional. 2005. $125 \mathrm{f}$. Dissertação (Mestrado em Educação)-Universidade Federal de São Carlos, São Carlos, 2005.

MARCOLINO, T. Q. A porta está aberta: aprendizagem colaborativa, prática iniciante, raciocínio clínico e terapia ocupacional. 2009. 307 f. Tese (Doutorado em Educação)Universidade Federal de São Carlos, São Carlos, 2009.

MARCOLINO, T. Q. O raciocínio clínico da terapeuta ocupacional ativa. Revista CETO, São Paulo, v. 13, n. 3, p. 14-25, 2012.

MARCOLINO, T. Q.; MIZUKAMI, M. G. N. Narratives, reflective processes and professional practice: contributions towards research and training. Interface, Botucatu, v. 12, n. 26, p. 541-547, 2008.

MUNROE, H. Clinical reasoning in community occupational therapy. British Journal of Occupational Therapy, London, v. 59, n. 5, p. 196-202, 1996.

ROBERTS, A. E. Approaches to reasoning in occupational therapy: a critical exploration. British Journal of Occupational Therapy, London, v. 59, n. 5, p. 233-236, 1996.

ROBERTSON, L.; GRIFFITHS, S. Problem solving in occupational therapy. In: ROBERTSON, L. (Ed).
Clinical reasoning in occupational therapy. Pondicherry: Wiley-Blackwell, 2012. p. 1-14.

ROGERS, J. C.; HOLM, M. B. Occupational therapy diagnostic reasoning: a component of clinical reasoning. The American Journal of Occupational Therapy, Bethesda, v. 45, n. 11, p. 1045-1053, 1991. http://dx.doi.org/10.5014/ ajot.45.11.1045

SCHELL, B. A. B.; SCHELL, J. W. Clinical and professional reasoning in Occupational Therapy. Philadelphia: Wolters Klumer/Lippincott Williams \& Wilkins Publishers, 2008.

SCHÖN, D. The reflexive practitioner. New York: Basic Books, 1983.

THOMPSON, B. Abductive reasoning and case formulation in complex cases. In: ROBERTSON, L. (Ed.). Clinical reasoning in occupational therapy. Pondicherry: Wiley-Blackwell, 2012. p. 15-30.

UNSWORTH, C. Using a head-mounted video camera to explore current conceptualizations of clinical reasoning in occupational therapy. The American Journal of Occupational Therapy, Bethesda, v. 59, n. 1, p. 31-40, 2005. http:// dx.doi.org/10.5014/ajot.59.1.31

WARD, J. The nature of clinical reasoning with groups: a phenomenological study of an occupational therapist in community mental health. The American Journal of Occupational Therapy, Bethesda, v. 57, n. 6, p. 625-634, 2003. http://dx.doi.org/10.5014/ajot.57.6.625

WENGER, E. Communities of practice: learning, meaning and identity. Cambridge: Cambridge University Press, 1998. http://dx.doi.org/10.1017/CBO9780511803932

\section{Notas}

${ }^{1}$ Conferência apresentada no II Simpósio Internacional de Pesquisa em Terapia Ocupacional, em 10 de agosto de 2012, no anfiteatro do Instituto de Psiquiatria do Hospital das Clínicas da Faculdade de Medicina da Universidade de São Paulo, com o título "A investigação do raciocínio clínico: Relevância para a clínica e para a formaçáo do terapeuta ocupacional." 